\title{
THE DELFT DESIGN FOR END OF LIFE LAB
}

\author{
Marieke SONNEVELD \\ Delft University of Technology
}

\begin{abstract}
In the future, medical technology will prolong our lives significantly, thereby changing our perspectives on death and dying, and will question the quality of life in its final stage. It might well be that we not only prolong life, but the dying process as well. More and more, people will need to make decisions about how they envision their end of life. The Delft Design for End-of-Life lab addresses these questions from a design perspective: how could design support the quality of life in its final stage, and how could design support people in preparing for that final stage and communicating about it? And more in general: how could design contribute to death awareness and literacy in our societies? This paper introduces the different aspects of End-of-Life care as a foundation for the Delft Design for End-of-Life Lab, describes the lab illustrated with several design examples, and concludes with the lessons learned from Design for End-of-Life that may be relevant for other domains of design.
\end{abstract}

\section{Keywords: Design for end-of-life, quality-of-life, design lab, design reflections}

\section{INTRODUCTION}

Medical technology focuses on improving human health and longevity, both for individual cases and overall for humankind. From an individual perspective medical technology focuses on prolonging life as much as possible, in the healthiest way. From the perspective of humankind, medical technology even seems to allow us to challenge our mortality: could we become immortal by merging ourselves with technology? From both perspectives, medical technology asks us to question the existential aspects of our living: the meaning and quality of our life [1]. Moreover, medical technology, due to its increasing power to prolong life, obliges us to be pro-active in deciding how we want to die, how we envision the final stage of our life: are we going to fight to extend our lives as much as possible? Or are we going to choose for quality over quantity in the final stage of our life?

Despite this longing for immortality, our mortality remains an important and inevitable aspect of our life and for some death and dying reveal what really matters in life [2]. Dying becomes an integrated part of living and is acknowledged as such. However, addressing death and dying in care as well as in individual lives is a difficult task. In professional as well as in personal settings, we tend to avoid the subject. 'A good death' implies a good communication between all those involved, which is often not the case. Due to this 'taboo' and lack of death-literacy, we often don't live the last stage of our lives the way we would have wanted to.

Design can play a powerful role in improving quality of death and dying. First, by developing interventions in the different domains of palliative care: providing physical comfort for patients, taking care of, and facilitating those social interactions that matter, taking care of the emotional well-being and supporting people in addressing the existential aspects of their life (figure 3). Next, design can be a powerful means to support the caregivers in the demanding task of taking care of the dying and facilitate people to communicate about death and dying. Also, on a societal level, design can contribute to death awareness and literacy [3].

Due to the potential of Design for the End-of-Life care, the Delft Design for End Life Lab was founded. In this lab, design students and design researchers join forces to explore how design can contribute to the quality of death and dying, thereby to the quality of life in its final stage.

This paper introduces the Delft Design for End-of-Life lab as a research and education platform, describing the goal and the structure of the lab, the design education approach and the design research vision, illustrated with six finalised projects that explore the domain of palliative care. The paper concludes on the lessons learned, for the future development of the Design for End-of-Life Lab and 
reflects on how end of life design projects contribute to perspectives on ethics in design(ing), on quality of life and on addressing sensitive topics in designing.

\section{CARE FOR THE END OF LIFE}

To set the stage for a Design Lab supporting quality of life in life's final stages, we need a framework to understand palliative care from a design perspective. This framework is introduced from three perspectives: the type of care developed over time, the people involved, and the domains of care.

\subsection{Development of care: from curative to palliative care}

Medical care is primarily focused on curative treatments: making people healthy again. In life threatening diseases, where a cure is no longer possible, the care will gradually shift from curative to palliative: providing comfort in coping with the disease. The transition from curative to palliative care gradually develops over time. When there is no longer curative care involved, the palliative care becomes hospice care. Hospice care does not stop at the death of a person but includes taking care of the body and of the people surrounding the dying person after death has occurred.

This model [4] allows us to see palliative and hospice care as an integrated part of life, starting before the terminal stage and lasting after a person died (figure 1).

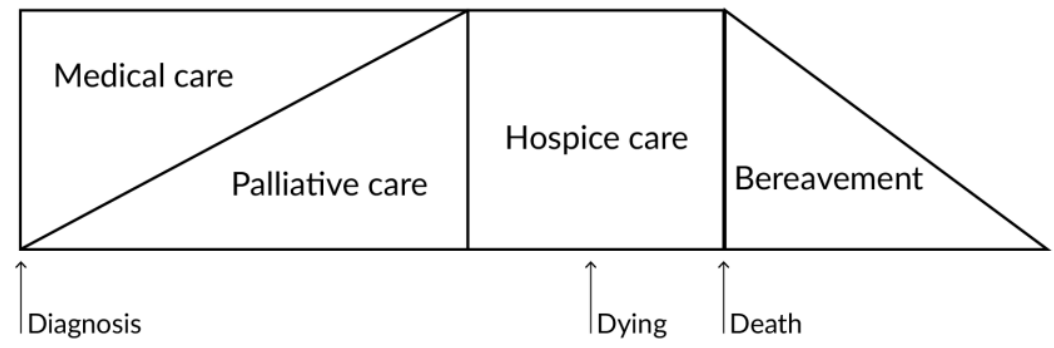

Figure 1. The transition from curative to palliative and hospice care

\subsection{People involved in palliative care}

Human centred design tends to put 'the human' in the centre of a social and societal context. Palliative care is based on a different perspective. It does not merely evolve around a person, as a user at the centre of a care process, but it takes the relations involved in care as a starting point. Care decisions take not only the patient, but also family, partners, (in)formal caregivers into account. The care is aimed at all people involved, from a relational perspective. Also, in designing for the end of life, the relational perspective will be the foundation of understanding human centred design [5].

In addition, these relationships and attitudes towards death and dying are shaped by our social, cultural and societal context (figure 2)

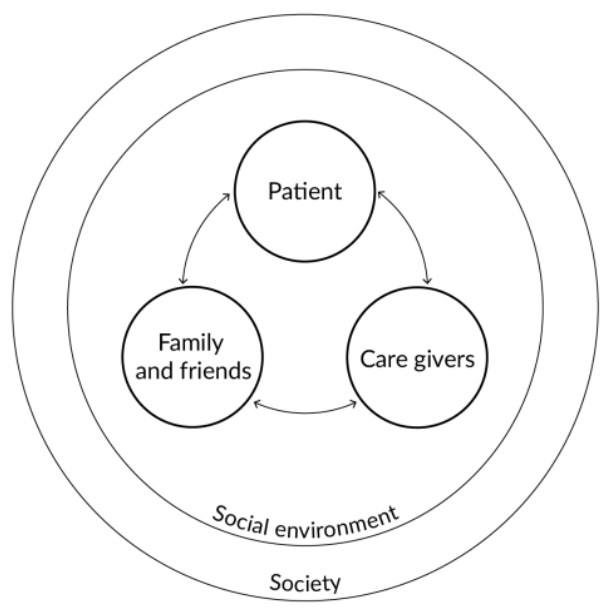

Figure 2. People involved from a relational perspective, in a social and societal context 


\subsection{The domains of end of life care}

End of life care is primarily aimed at providing comfort and has a holistic approach, integrating four different domains of care: physical, psychological/emotional, social, and spiritual (figure 3) [6]. The domains are intertwined and have an important impact on each other, for example, taking care of physical comfort in looking for the right body posture will influence the social interactions with one's surroundings. And care on an emotional level (for example care for the fear of dying) cannot be seen as detached from existential aspects such as questioning the meaning of one's life.

Designing for the end of life will have this same holistic and integrated approach.

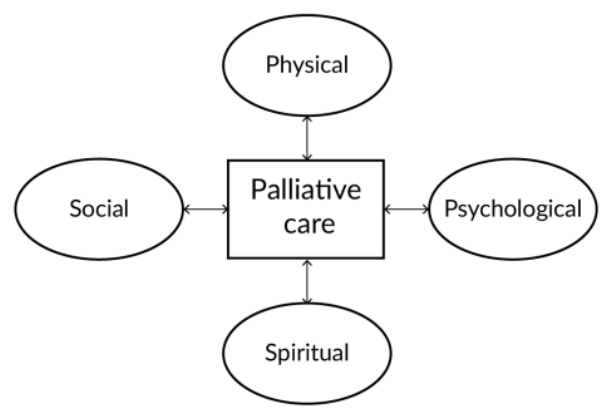

Figure 3. Domains of palliative care: an integrated approach

\section{THE DELFT DESIGN FOR END-OF-LIFE LAB}

The Delft Design Lab was founded in 2017, creating a research and education platform addressing specific end of life themes. The projects are primarily set up as design graduation projects, and involves other educational settings such as dedicated electives, research internships, international workshops, and so on. The lab is organised around researchers from the faculty, in collaboration with organisations and companies outside the university, to ensure the connection with the practice of palliative care.

\subsection{Vision on the Design for End-of-Life Lab projects}

The Design for End-of-Life Lab sees quality of dying as a shared responsibility of all involved. This is in line with the philosophy of the Compassionate Communities Network. This movement shows that communities that develop death literacy develop an inclusive, social attitude toward caring for each other in the last stages of life [7]. Also, the need for death literacy of all involved is one of the foundations of the Design Lab: contribution to death literacy should always be part of the projects developed in the lab.

This death awareness and literacy, however, cannot be enforced upon students. End of life is a sensitive topic. The lab ensures that students approach the topic by choice, when they feel it is appropriate for them. Also, the set-up of the projects, content- and process-wise, is structured in collaboration with the students involved, to ensure a match with one's personal perspectives and values. The goals and motivation of the students are thereby guiding principles.

\subsection{Examples of Design for End-of-Life projects}

This section will introduce some of the Design for End-of-Life projects, to illustrate the scope of the lab and the possibilities of how design can contribute to the domain of end of life care. The projects introduce the topics addressed in the lab and show the human-relation centred Design for End-of-Life approach: focusing on the relations and interactions between people involved in end of life care. Each project emphasises on an overall theme emerging from designing for end of life, themes that are relevant in any domain of life, such as trust, security, affection, autonomy and privacy.

Also, in all projects involved, all stakeholders are involved throughout the project, during the research as well as during the design phase. 


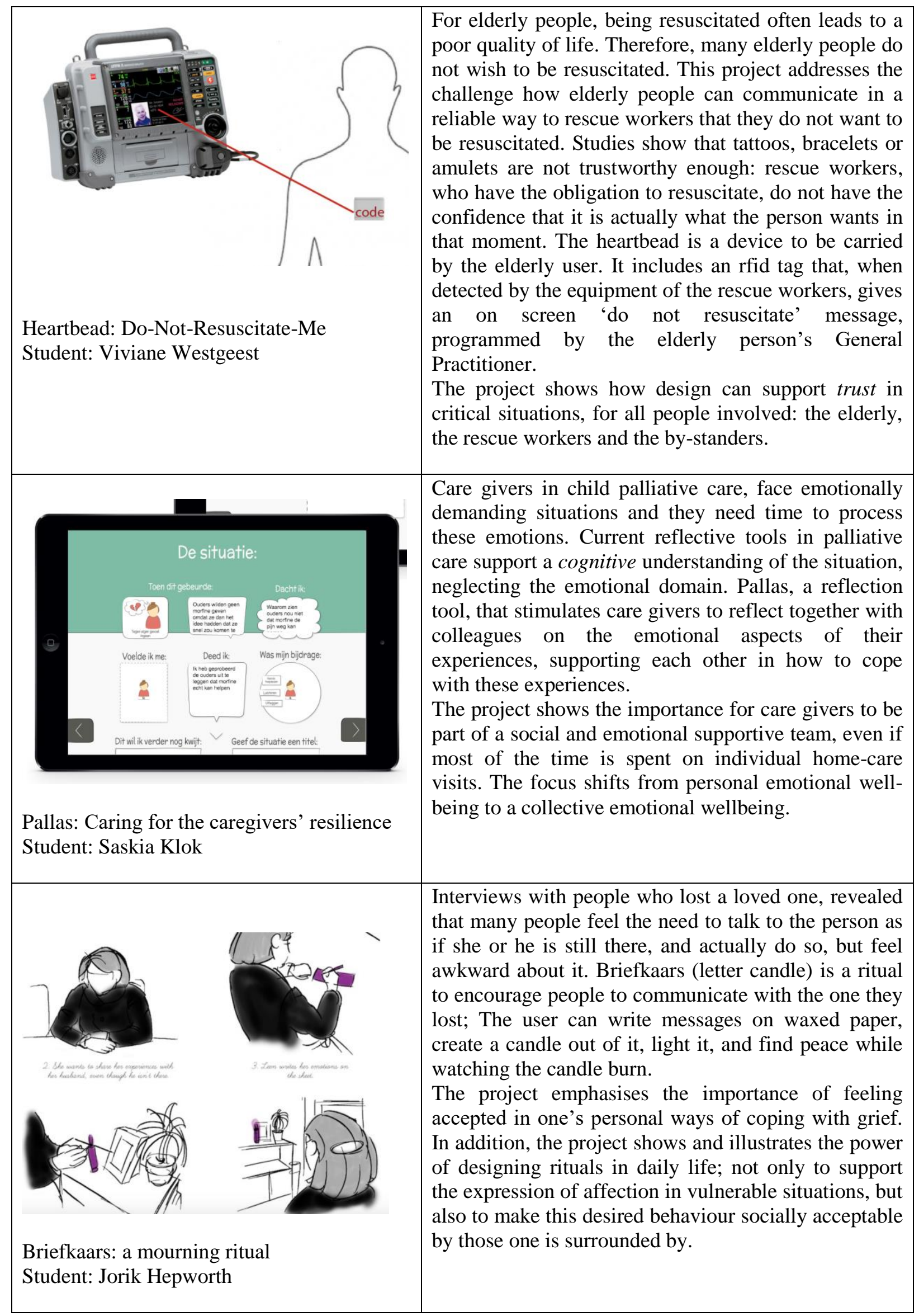




\begin{tabular}{|c|c|}
\hline 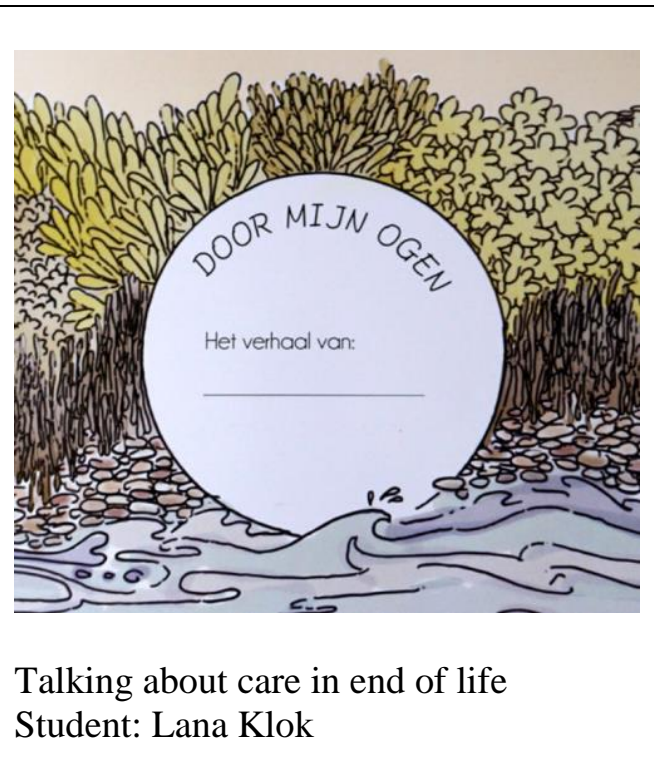 & $\begin{array}{l}\text { Quality of life in the end of life depends on how one } \\
\text { prepares oneself for life's final stage. Also, when one } \\
\text { does not anticipate, healthcare decisions may not be in } \\
\text { line with one's personal values. However, it is } \\
\text { difficult to discuss the topic, with care givers, relatives } \\
\text { and friends. 'Met mijn ogen' is a conversation tool that } \\
\text { allows elderly people to express their 'desired quality } \\
\text { of life' to their care givers, by creating a value-based } \\
\text { portrait of themselves, based on their past and present } \\
\text { life This portrait is used as a basis to make future care } \\
\text { decisions together. } \\
\text { The project shows the importance of creating a } \\
\text { 'socially safe' place for people to be able to reflect on } \\
\text { the values in their lives, as these reflections emerge } \\
\text { from the conversations with the care givers. Also, the } \\
\text { project shows the importance in care of addressing the } \\
\text { link between past, present and future. }\end{array}$ \\
\hline (3) & $\begin{array}{l}\text { In Paediatric Intensive Care Units (PICU), parents } \\
\text { often feel powerless, and wish to do something to } \\
\text { support, but do not know how. Twinkle is a projecting } \\
\text { lamp that allows parents to alter a PICU space for a } \\
\text { short while in a magical environment where parents } \\
\text { and children can have a moment of their own, to be } \\
\text { together in their bubble. Medical staff are included in } \\
\text { the system, to ensure their support. } \\
\text { (Project in Collaboration with the Critical Alarms Lab) } \\
\text { The project acknowledges the importance of including } \\
\text { parents in the circle of care, and to see them as } \\
\text { partners in the well-being of the children and of } \\
\text { themselves. Simultaneously it shows the need for } \\
\text { privacy and intimacy and how design can meet these } \\
\text { needs in an environment primarily focused on } \\
\text { efficiency. }\end{array}$ \\
\hline
\end{tabular}

\section{IMPLICATIONS FOR DESIGN EDUCATION}

The Delft Design for End-of-Life Lab primarily aims at improving quality of life through design, in life's final stage. This section will elaborate on the synergy between design insights within the domain of end of life and design in general.

\subsection{A trans-disciplinary approach}

Design for end of life is more than a multi-disciplinary approach, where people from different disciplines join their expertise to innovate. In design for end of life, different disciplines involved have to be able to understand each other in a more fundamental way: designers transcend their own discipline and integrate in a larger set of disciplines, becoming part of the other disciplines. This skill of transcending disciplines is valuable for design in other healthcare domains as well.

\subsection{Quality of life in perspective}

In design for end of life, one becomes aware of seeking the balance between quality and quantity of life [8]. Students who reflected on this dilemma, reflected on the value of this insight for other domains of design, such as other health care applications, education, sports, and so on. Quality of life is put in a different perspective, and less compromised by fear of loss or the fear of risks. Students even reflected that participating in end of life projects affected them personally, becoming aware of 
the quality of their own life, and what matters to them. Again, this is of value for them as designers in other domains.

\subsection{Ethics in perspective}

Design for end of life will often address moral dilemmas, not only between the different stakeholders involved, but also internally within the designer. In palliative care, these moral dilemmas are approached from a care ethics perspective: it is not about choosing for one position over the other, but about how to find a way to reconcile the different voices, creating a polyphone harmony [9]. This insight in care ethics is a valuable insight for designers, allowing for compassion in design, not only in design for care, but also for design in general.

\subsection{Time in perspective}

In design we tend to strive for efficiency and effectiveness, not only regarding the design results, but also the way we design. In both, project process and project results, time should not be wasted, but used in the most fruitful manner. The design for end of life projects put time in a different perspective. Efficiency and effectiveness are not key, but patience; the patience to address the difficult questions, to allow the process to happen. Insights in end of life matters can generally not be achieved through time pressure but need time to develop. This patience in design and in designing is a valuable insight to extrapolate from design for end of life to design in general, acknowledging that any design project actually deals with these existential dilemma's that are difficult to address,

\section{THE FUTURE OF EDUCATION IN DESIGNING FOR END OF LIFE}

Designing for end of life, for death and dying, for loss and bereavement, are sensitive and demanding topics that seem difficult to address. However, experiences of people working in palliative care also shows their positive impact; putting life in perspective, addressing its meaning and questioning its values [ref]. End of life care acknowledges death and dying as an integrated, meaningful part of life, and thereby inspires to live. One could also conclude that understanding the art of dying inspires the understanding of the art of living. The Design for End-of-Life Lab will develop itself further based on this insight. Like for any other domain, Design for End-of-Life may not appeal to every student, and some might not be ready to study the topic. The lab should therefore stay sensitive to how students are involved, making sure that students are not overwhelmed. However, the projects in the lab are undertaken in the confidence that if a student is at ease in the Design for End-of-Life Lab, the lab, for a while, can become her school of life.

To achieve this confidence and to support the students in addressing these sensitive topics, for students as well as for other researchers, teachers and stakeholders involved, the lab will continue in developing appropriate tools and methods that allow for involvement of personal values, beliefs and perspectives, yet simultaneously creating a common ground to build up on.

\section{REFERENCES}

[1] Gawande A. (2014). Being mortal: medicine and what matters in the end. New York: Metropolitan Books, Henry Holt and Company.

[2] Steiner S. (2012). Top 5 regrets of the dying. https://www.theguardian.com/ lifeandstyle/2012/Feb/01/top-five-regrets-of-the-dying. Accessed on 17/12/2018.

[3] Noonan K., Horsfall D., Leonard R. and Rosenberg J.R. (2016) Developing Death Literacy. Progress in Palliative Care 24 (1).

[4] Buss M.K., Rock L.K. and McCarthy E.P. (2017). Understanding Palliative Care and Hospice: a review for primary care providers. Mayo Clinic Proceedings, Vol 92(2). 280-286.

[5] Walter J.K. and Ross L.F. Relational Autonomy: Moving Beyond the Limits of Isolated Individualism. Paediatrics 2014;133; S16.

[6] WHO Definition of Palliative Care. https://www.who.int/cancer/palliative/definition/en/. Accessed on 11/03/2019

[7] Ael J. (2018). Compassionate communities and End of Life Care. Clinical Medicine. Vol 18,1: 6-8.

[8] Hales S., Zimmermann C. and Rodin G. (2008). The Quality of Dying and Death. Arch Intern Med. 168 (9): 912-918.

[9] Gilligan C. (1993). In a different voice: psychological theory and women's development. Cambridge, Mass.: Harvard University Press. 